\title{
Massive 3D models and physical data for building simulation at the urban scale: a focus on Geneva and climate change scenarios
}

\author{
J. R. Vázquez-Canteli \& J. H. Kämpf \\ Solar Energy and Building Physics Laboratory (LESO-PB), \\ École Polytechnique Fédérale de Lausanne (EPFL), Switzerland
}

\begin{abstract}
At a time when governments are pursuing increasingly ambitious energy efficiency goals, building energy simulation at the urban scale, combined with the high availability of physical data, can help in performing this task. The purpose of this study is to describe the methodology used to create a geometrical 3D and physical model for the city of Geneva, and to analyze the energy-saving potential of several refurbishment measures, including the installation of more solar PV panels, for different climatic scenarios. Different sources of data are used to build a PostgreSQL database with the physical and geometrical characteristics of the buildings. The virtual models are simulated with CitySim, a program that estimates the energy demand for heating, cooling, and lighting of every building on an hourly basis. The models include, but are not limited to, the shadowing effect among the buildings, the passive solar gains through glazing, the internal gains due to occupants' activities, the solar reflectance and infrared emissivity of the surfaces, and the materials that provide the buildings with insulation from the outdoors. This research will also provide some results that can be used by the municipal authorities of Geneva as a reference to quantify the decrease of the energy demand that they can expect to achieve in the next years.

Keywords: residential energy use, sustainable development, $\mathrm{CO}_{2}$ reduction strategies, renewable energy technologies, building physics, cities, solar PV.
\end{abstract}

\section{Introduction}

Switzerland is taking bold decisions to gradually phase out nuclear power and to reduce their greenhouse gas emissions by $20 \%$ by 2020 . Since moving towards an 
energy mix in which the baseload generation will be satisfied by gas-fired power plants seems to be a good alternative [1], further efforts must be made in order to reduce $\mathrm{CO}_{2}$ emissions. Most of Switzerland's energy-related $\mathrm{CO}_{2}$ emissions come from transportation and space heating. Therefore, new measures towards a more efficient use of energy should be mainly adopted in these two areas.

National energy standards (such as SIA 380/1:2009 inspired by a MINERGIE label) aim to decrease the heating demand in buildings by providing strict limits in the energy consumption for new and retrofitted buildings. In addition, many boilers are being replaced by heat pumps or by more efficient energy conversion units. Also, the installation of solar PV-T systems will help to supply DHW and to reduce the dependency of many buildings on the grid. More effective HVAC controllers are also a promising approach to reduce the energy needs in the buildings [2], and electric vehicles will possibly be used as energy storage systems connected to the grid in the near future. For all of these reasons, the cities' energy systems will increase in complexity, whereas the dependency of the heating and cooling demands on the ambient temperature will weaken. Instead, the energy demand will depend more on stochastic behaviors such as solar gains and occupancy profiles. Building simulation at the urban scale is a powerful tool to predict the behavior of the cities of tomorrow, allowing regulators to develop more effective policies to manage the energy supply and demand of the buildings on an urban scale $[3,4]$.

Urban simulation can help Geneva municipal authorities to quantify the decrease in energy demand that they can expect to achieve in their city thanks to different refurbishment scenarios. Climate change estimations provided by the Meteonorm software are helpful to evaluate the expected effect of global warming on the heating and cooling needs of the city. Some models based on PostgreSQL databases and GIS have been used before to model other cities in Switzerland [5, $6]$.

This paper describes the methodology to realize the geometrical 3D and physical model for the city of Geneva, analyzes the energy-saving potential of different refurbishment measures, and provides some useful information about the total energy generation that could be achieved thanks to the installation of more PV panels. The results will be based on a particular district of Geneva.

\section{Methodology}

In order to create a geometrical 3D and physical model that we can simulate for solving the energy flows, it is necessary to store that information in a database with accurate data of the buildings.

\subsection{Creation of the database}

PostgreSQL is a complete DBMS which allows a wide range of SQL functionalities. The PostGIS module provides additional geometry types and functions to handle them. The database was completed with data from the information system of the territory of Geneva (SITG) [7] and from the Federal 
Register of Buildings and Dwellings (RegBL) [8]. Figure 1 depicts graphically the structure of the database with a unique identification number or EGID assigned to each building, all pointing to a given district, scenario to be simulated, and occupancy type (i.e. residential, commerce). The grounds of the city and the walls of the buildings were defined as composites, where each composite is formed by several layers, and each layer is made of a specific material.

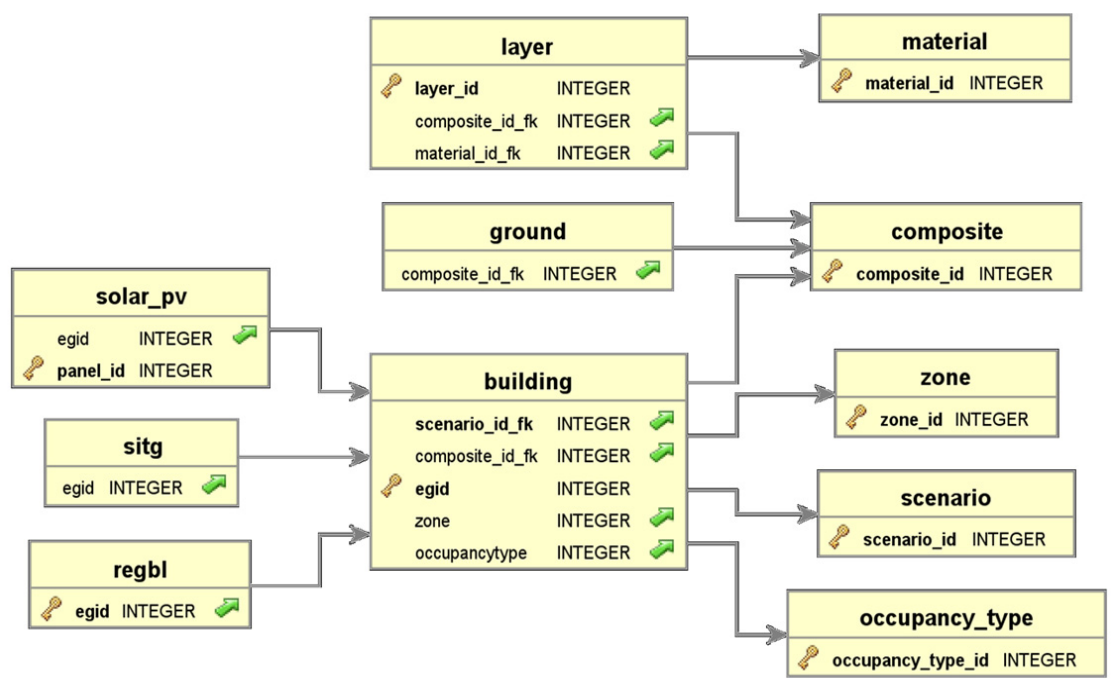

Figure 1: EV diagram of the database.

The year of construction of each building is useful to estimate the composition of the walls and the roofs, the natural ventilation rates, the characteristics of the windows, and the glazing ratios based on an existing study [9] (as table 1 shows).

Data of the heights, number of floors, number of occupants, type of building, and year of construction and refurbishment were obtained from SITG and RegBL, while the information about the footprint geometries was only available in SITG. For some buildings, the height and the number of floors were missing. In these cases $(0.54 \%$ of the buildings), these parameters were estimated using the average values of the buildings in the same district. When the period of construction was not available ( $1 \%$ of the buildings), it was estimated using a Monte Carlo approximation based on the age of the buildings located in the same district.

Table 1: Composition of the walls for buildings built between 1900 and 1945 [9].

\begin{tabular}{|c|l|c|c|c|c|}
\hline $\begin{array}{c}\mathrm{U}_{\text {wall }} \\
\left(\mathrm{W} / \mathrm{m}^{2} \mathrm{~K}\right)\end{array}$ & Layer material & $\begin{array}{c}\text { Thick. } \\
(\mathrm{m})\end{array}$ & $\begin{array}{c}\lambda \\
(\mathrm{W} / \mathrm{m} \cdot \mathrm{K})\end{array}$ & $\begin{array}{c}\mathrm{Cp} \\
(\mathrm{J} / \mathrm{kg} \cdot \mathrm{K})\end{array}$ & $\begin{array}{c}\text { Density } \\
\left(\mathrm{kg} / \mathrm{m}^{3}\right)\end{array}$ \\
\hline \multirow{3}{*}{0.94} & Insulating rendering & 0.02 & 0.08 & 1000 & 300 \\
\cline { 2 - 6 } & Rubble masonry & 0.40 & 0.81 & 1045 & 1600 \\
\cline { 2 - 6 } & Insulating plaster & 0.02 & 0.21 & 800 & 900 \\
\hline
\end{tabular}


The windows were defined in the model using the U-value of the glass, eqn. (1), the g-value, and the glazing ratio with respect to the wall (as shown in table 2).

Table 2: $\quad$ Parameters used to model the windows.

\begin{tabular}{|l|c|c|c|c|}
\hline \multicolumn{1}{|c|}{ Period } & $\begin{array}{c}\mathrm{U} \text {-value } \\
\left(\mathrm{W} / \mathrm{m}^{2} \cdot \mathrm{K}\right)\end{array}$ & g-value & Glazing ratio & Window to wall ratio \\
\hline Before 2000 & 2.3 & 0.47 & 0.175 & 0.25 \\
\hline After 2000 & 1.7 & 0.49 & 0.245 & 0.35 \\
\hline
\end{tabular}

$$
U_{\text {glass }}=\frac{\text { fenestration ratio }}{\text { glazing ratio }} \cdot U_{\text {window }}
$$

The type of building is useful to estimate the occupancy and the electricity consumption profiles, the minimum ventilation rates required, and the number of occupants based on the values of the SIA2024 norm (as shown in table 3). The number of occupants of each building was calculated as the average between the value provided by SITG and RegBL, and the value estimated from the norm. If the ratio between these two values was greater than $50 \%$ of the value in the SIA2024, only the value from the norm was used.

Table 3: Values based on the SIA2024 for residential buildings and offices.

\begin{tabular}{|l|c|c|c|c|}
\hline $\begin{array}{l}\text { Type of } \\
\text { building }\end{array}$ & $\begin{array}{c}\text { Surface/ } \\
\text { pers. }\left(\mathrm{m}^{2}\right)\end{array}$ & $\begin{array}{c}\text { Electric } \\
\text { pow. }\left(\mathrm{W} / \mathrm{m}^{2}\right)\end{array}$ & $\begin{array}{c}\text { Ventilation } \\
\text { day }\left(\mathrm{m}^{3} / \mathrm{m}^{2} \cdot \mathrm{h}\right)\end{array}$ & $\begin{array}{c}\text { Ventilation } \\
\text { night }\left(\mathrm{m}^{3} / \mathrm{m}^{2} \cdot \mathrm{h}\right)\end{array}$ \\
\hline Residential & 50 & 2 & 0.6 & 0.3 \\
\hline Office & 14 & 7 & 2.6 & 0 \\
\hline
\end{tabular}

The shortwave reflectance of all the walls was set to $25 \%$, and the indoor minimum and maximum comfort temperatures were set to $21.0^{\circ} \mathrm{C}$ and $26.0^{\circ} \mathrm{C}$.

\subsection{Creation of the geometrical 3D and physical model}

After creating a database, a java program was used to write an XML file that provides the simulation software CitySim with all the information of the physical and geometrical characteristics of the buildings. CitySim was developed at EPFL [10], and computes an estimation of the energy demand for heating, cooling, and lighting of every building. After the simulation, CitySim returns a text file with all the results for every floor and building on an hourly basis. These results are put into the database and linked to each building by the EGID number. This allows analysis of the results in combination with the physical characteristics of the buildings. A geometrical 3D and physical model of one district of Geneva was created (fig. 2) in order to perform a calibration with real data of the heating demands, and to analyze the behavior of the buildings in different scenarios. 


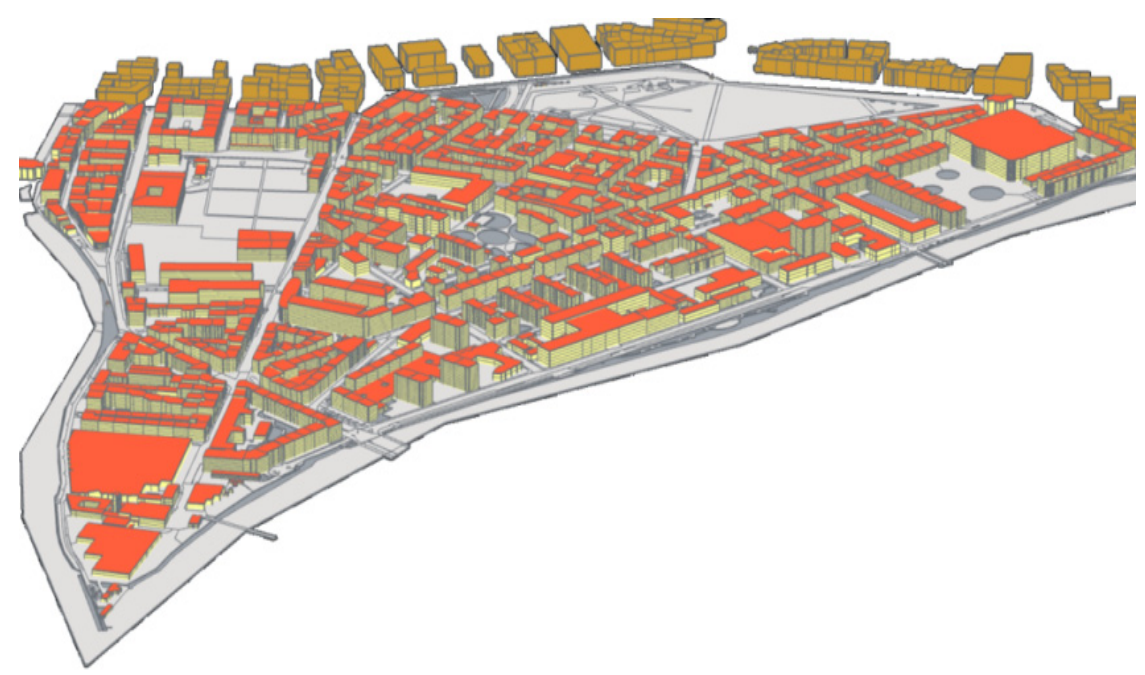

Figure 2: Geometrical 3D and physical model of the Junction district in Geneva.

\subsection{Calibration of the model}

In order to calibrate the model, the buildings were classified based on their period of construction and their type of use. These two features have a great impact on the total ventilation rate of the buildings, which is difficult to estimate and can change the heating and cooling demands dramatically. The values of the minimum ventilation requirements were available in the SIA2024 norm, while the initial natural ventilation rates were obtained from a previous study [9]. Table 4, and table 5 show the median value of the $\log _{2}$ of the quotient between the simulated heat demand $\left(\mathrm{Q}_{\text {sim }}\right)$ and the actual value $\left(\mathrm{Q}_{\text {real }}\right)$, which is used to measure the error. The number of buildings is expressed between brackets.

Table 4: Results from the calibration for different periods of construction.

\begin{tabular}{|l|c|c|c|c|}
\cline { 2 - 5 } \multicolumn{1}{c|}{} & \multicolumn{2}{c|}{ Before calibration } & \multicolumn{2}{c|}{ After calibration } \\
\hline Period & $\eta_{\text {nat }}\left(\mathrm{h}^{-1}\right)$ & $\log _{2}\left(\mathrm{Q}_{\text {sim }} / \mathrm{Q}_{\text {real }}\right)$ & $\eta_{\text {nat }}\left(\mathrm{h}^{-1}\right)$ & $\log _{2}\left(\mathrm{Q}_{\text {sim }} / \mathrm{Q}_{\text {real }}\right)$ \\
\hline$<1915(192)$ & 0.700 & -0.410 & 1.078 & -0.034 \\
\hline $1915-1945(136)$ & 0.700 & -0.526 & 1.179 & -0.051 \\
\hline $1946-1960(79)$ & 0.600 & -0.743 & 1.224 & -0.007 \\
\hline $1961-1970(79)$ & 0.550 & -0.692 & 1.300 & 0.130 \\
\hline $1971-1980(29)$ & 0.500 & -0.696 & 1.191 & 0.074 \\
\hline $1981-1990(42)$ & 0.400 & -1.080 & 1.093 & -0.040 \\
\hline $1991-2000(34)$ & 0.350 & -0.961 & 0.920 & -0.010 \\
\hline$>2000(24)$ & 0.300 & -0.434 & 0.599 & -0.005 \\
\hline
\end{tabular}




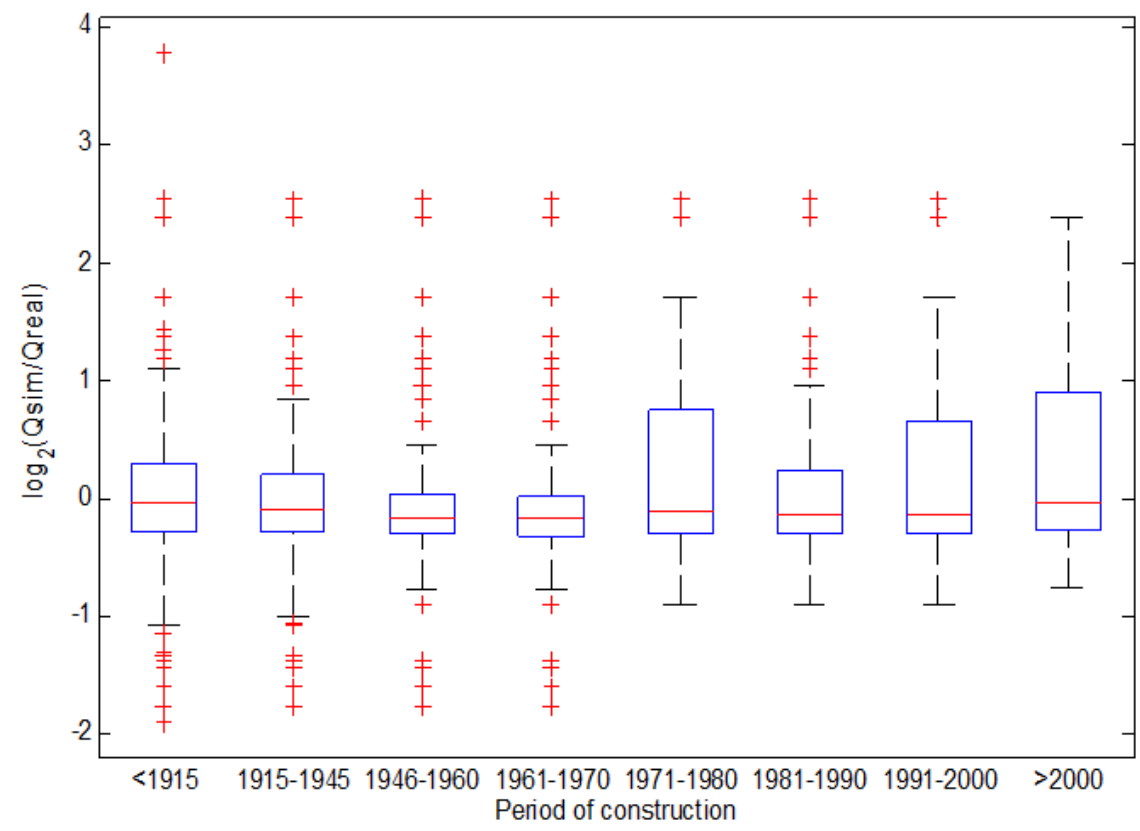

Figure 3: Error after the calibration for different periods of construction.

The total ventilation rate was calculated using eqn. (3), where $\gamma_{\eta n a t}$ and $\gamma_{\text {vent }}$ are two multiplier coefficients adjusted during the calibration process (table 5). Before the calibration, these multipliers had a value of one.

$$
\text { Ventilation }=\max \left\{\gamma_{\eta_{\text {nat }}} \cdot \eta_{\text {nat }}, \quad \gamma_{\text {vent }} \cdot \text { Ventilation }_{\text {SIA2024 }}\right\}
$$

Table 5: $\quad$ Results from the calibration for different types of buildings.

\begin{tabular}{|l|c|c|c|c|}
\cline { 2 - 5 } \multicolumn{1}{c|}{} & Before calibration & \multicolumn{3}{c|}{ After calibration } \\
\hline Type of building & $\log _{2}\left(\mathrm{Q}_{\text {sim }} / \mathrm{Q}_{\text {real }}\right)$ & $\gamma_{\text {nnat }}$ & $\gamma_{\text {vent }}$ & $\log _{2}\left(\mathrm{Q}_{\text {sim }} / \mathrm{Q}_{\text {real }}\right)$ \\
\hline Commercial (42) & 0.349 & 0.525 & 0.600 & -0.024 \\
\hline Education (30) & 0.002 & 0.542 & 0.628 & -0.025 \\
\hline Residential (442) & -0.733 & 1.067 & 1.737 & -0.020 \\
\hline Office (45) & -0.074 & 0.605 & 0.669 & 0.112 \\
\hline Hotel (3) & -0.466 & 0.970 & 1.591 & 0.011 \\
\hline Restaurant (3) & 0.273 & 1.057 & 0.815 & -0.089 \\
\hline Other (50) & 0.134 & 0.440 & 0.360 & -0.034 \\
\hline
\end{tabular}




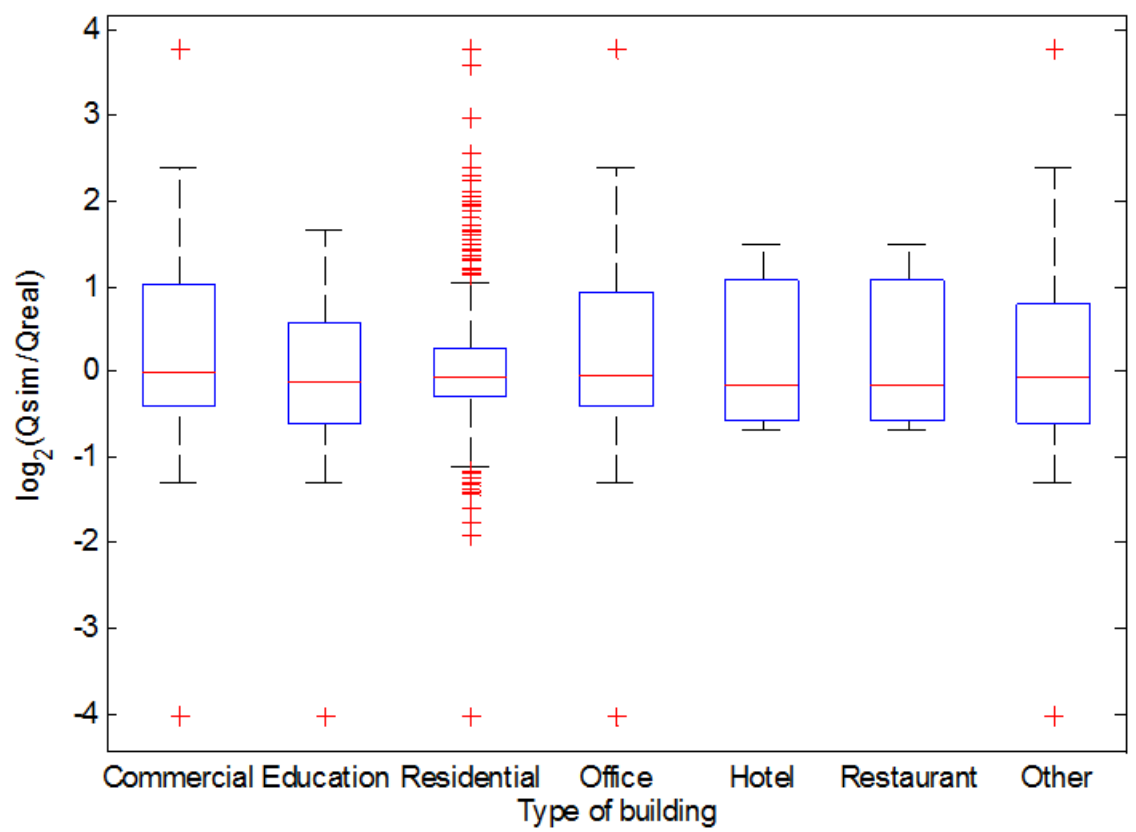

Figure 4: $\quad$ Error after the calibration for different types of buildings.

\section{Results and discussion}

From the calibration, we can observe that the heating demand of $50 \%$ of the residential buildings has a margin of error of about $\pm 15 \%$, as shown in fig. 4 . Once the model was calibrated, several refurbishment and climate change scenarios were analyzed. These analyses can be used by the municipal authorities of Geneva as a reference to quantify the decrease of the energy demand that they can expect to achieve in the next years if they adopt similar measures.

In the low refurbishment scenario, all the windows are triple glazed $\left(\mathrm{U}_{\text {window }}=\right.$ $0.87 \mathrm{~W} / \mathrm{m}^{2} \cdot \mathrm{K}$ and $\mathrm{g}_{\text {window }}=0.6$ ), while the high refurbishment includes triple glazed windows, increased wall insulations $\left(\mathrm{U}_{\text {wall }}=0.2 \mathrm{~W} / \mathrm{m}^{2} \cdot \mathrm{K}\right)$ and lower natural ventilation rates $\left(\eta_{\text {nat }}=0.3 \mathrm{~h}^{-1}\right)$ in all the buildings. Furthermore, PV panels were installed on all the available surfaces of the roofs with a gross annual irradiation greater than $1000 \mathrm{kWh} / \mathrm{m}^{2}$. The panels considered were SunPower X21-345, which have an efficiency of $21.5 \%$. The heat pumps used in this model have a technical efficiency of $30 \%$, a ground source with vertical pipes from $5 \mathrm{~m}$ to $10 \mathrm{~m}$ deep in a soil with a thermal diffusivity of $0.07 \mathrm{~m}^{2} /$ day, and a target temperature of $55^{\circ} \mathrm{C}$.

The heating demand of this district would decrease due, in part, to the effects of climate change, while the cooling demand will increase (as shown in fig. 5). However, in all the scenarios considered, the predicted cooling demand would still be too low to justify the wide implementation of cooling systems in this district. 
In 2050, increasing the insulation of the walls and reducing the infiltration rates would result in lower cooling demands of the buildings. Therefore, the better insulation of these buildings would reduce the effect of the outdoor temperature on the indoor temperature, more than it would increase the heating due to the internal gains.

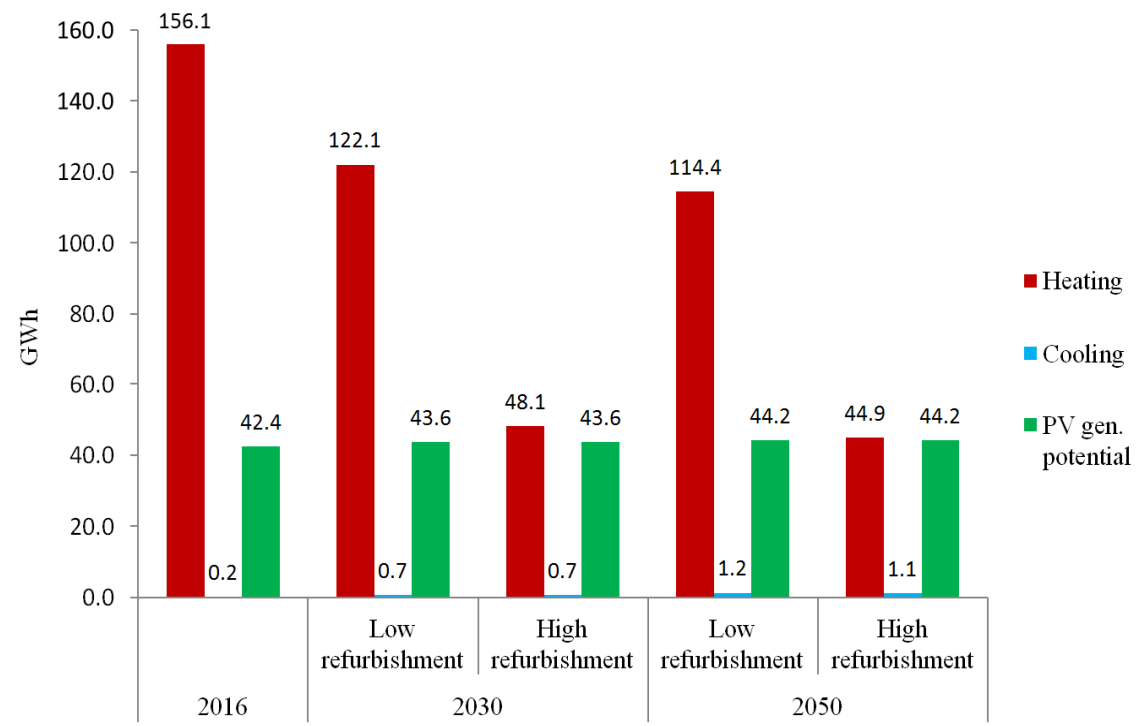

Figure 5: Energy demand and solar PV potential for different scenarios.

It is remarkable how it would be possible to achieve similar values of heating demand and energy generation from solar PV if the buildings were deeply refurbished. In 2050, considering a high refurbishment scenario and the heating demand to be supplied only by heat pumps, the annual electricity generation of the buildings would exceed their electricity demand. Therefore, with these assumptions, it would be possible to achieve an annual surplus of electricity generation of $4.9 \mathrm{GWh}$ if all the solar PV potential of the roofs were used. However, one of the limitations of this model is that, due to the lack of data about the geometries of the roofs, all the PV panels were oriented horizontally.

Solar PV panels will not always generate enough electricity to supply the whole demand of a building, whereas in other times the generation will surpass the demand. Therefore, it is interesting to analyze the average hourly surplus and shortage of electricity in the whole district (fig. 6).

During the daytime, from $9 \mathrm{~h}$ to $17 \mathrm{~h}$, there is more electricity being generated than being consumed. However, there are still many buildings that, due to their low PV potential or high energy demand, are not independent from the grid during this period. A well-coordinated electrical distribution network could help in reducing the number of buildings whose electrical demand is not satisfied by solar PV panels. A maximum of 27.2 MWh of this electricity could be redistributed 
every day, on average, among the buildings of this same district that would need it during the daytime. The remaining $69.4 \mathrm{MWh}$ of surplus energy could be stored in the buildings or in centralized systems, with the objective of using it during the periods of shortage. Heating up water to store it in tanks could be an option, while it is possible that part of this electricity could be used in the future to charge the batteries of electric vehicles.

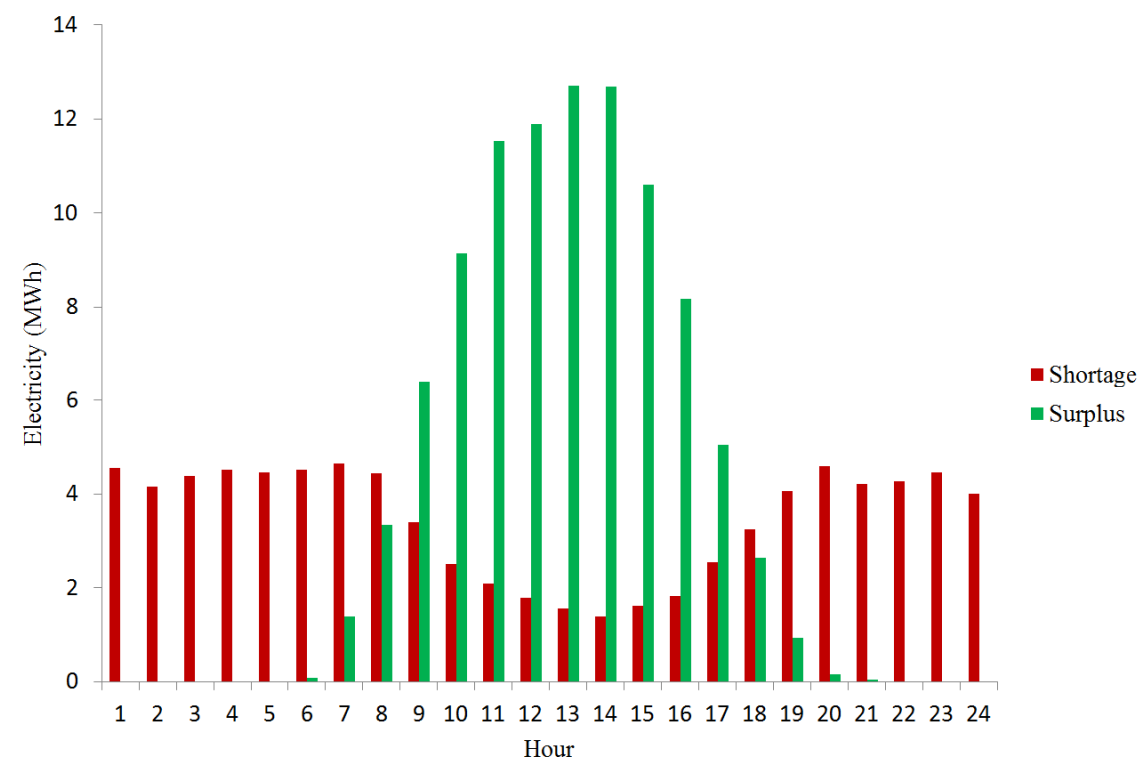

Figure 6: Estimation of the average hourly electricity shortage and surplus for the Junction district in 2050 and for a high refurbishment scenario.

High buildings with a small roof surface will probably need more energy that they will be able to generate, while buildings with a higher surface-height ratio will generate more than they will need (fig. 7).

In this case, the net electricity consumption is not uniformly distributed. Some buildings, located on the west part of the district, have the potential to generate much more energy that they would need. Municipal authorities can take advantage of this potential, and adopt policies that promote the installation of centralized energy storage systems near these buildings. This measure, combined with the existing policies of building refurbishment and the installation of more PV panels on all the roofs, can drastically reduce the dependency of this district on nonrenewable energy technologies. 


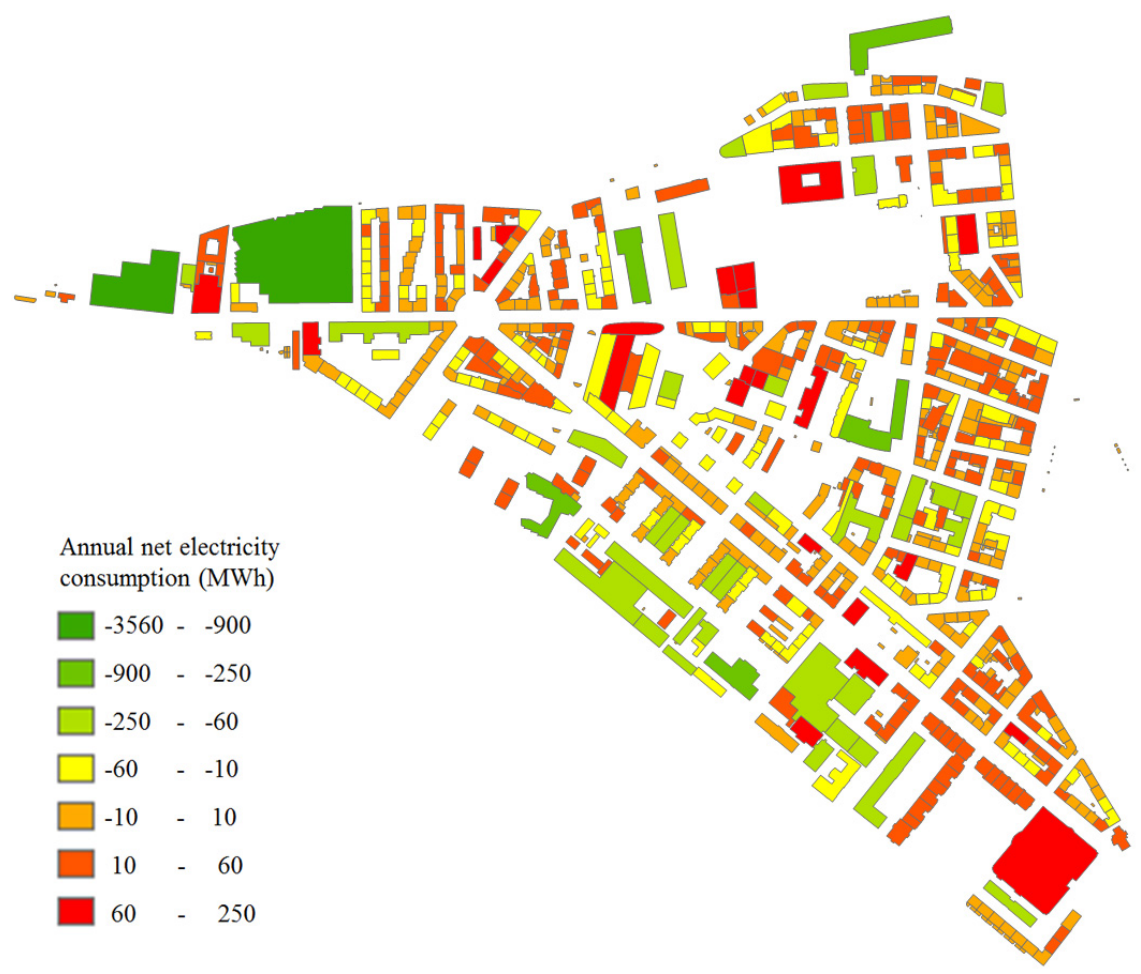

Figure 7: Map of the estimated annual net electricity consumption in the Junction district for a high refurbishment scenario in 2050.

\section{Conclusion}

Building simulation at the urban scale is a powerful tool to simulate the energy needs and generation potential of cities. PostgreSQL databases can store all the geometries of the buildings and their physical characteristics. Once the geometrical 3D and physical model is realized and calibrated, it can be simulated to obtain valuable information about the energy needs or generation of the buildings in different pre-defined scenarios. These data can be stored in the database together with the physical characteristics of the buildings for further analysis. For these models to be useful, the availability of accurate information regarding the physical characteristics of the buildings and their geometries is crucial. The results of the calibration show how it was possible to model the residential buildings accurately with the information that was available. However, it is more difficult to achieve this accuracy for other types of buildings, especially for those in which the stochastic behavior of the occupants is more unpredictable and has a greater impact on the heating demand.

The energy demand and generation of a district in Geneva were studied for different refurbishment scenarios, taking into account the expected effects of 
climate change in 2030 and 2050. These scenarios included an ideal case with the implementation of PV panels on every roof, and the use of heat pumps in every building. These measures were proven to drastically reduce the energy demands of the buildings, while increasing their generation of electricity above the overall annual energy consumption of the district. However, this potential energy surplus is not uniformly distributed. Some buildings have a much greater potential for installing PV panels than others, while certain buildings with smaller rooftop areas and higher heights would not be able to generate more electricity than they would consume. Municipal authorities of Geneva must take into account these asymmetries to adopt policies that promote an efficient distribution of PV panels, energy storage systems, and adequate interconnections in the energy distribution network.

Taking maximum advantage of the buildings with the highest solar potential, and installing centralized energy storage systems, such as water heat tanks, near them would be a possible good solution. In this case, a combination of PV panels and solar heaters would be a good approach. The stored heat can be redistributed through a district heating network or converted into electricity and distributed through the electrical power grid when the energy demand is higher. Further analysis can be developed with thermo-economic optimization techniques to find an optimal solution.

\section{Acknowledgements}

Particular thanks go to Nahid Mohajeri for providing the real data of the heating demands in the Junction district that were used for the calibration of the model. The source of these data is SITG and UniGE.

The authors would like to acknowledge the advice of Prof. François Maréchal on the presented work.

\section{References}

[1] Energy Policies of IEA Countries, Switzerland; International Energy Agency, 2012 Online. www.iea.org/publications/freepublications/ publication

[2] Prívara, S., Šroký, J., Ferkl, L. \& Cigler, J. Model predictive control of a building heating system: The first experience, Elsevier: Prague and Pilsen, p. 564, 2010.

[3] Karnouskos, S. \& Nass de Holanda, T. Simulation of a Smart Grid City with Software Agents, Third UK Sim European Symposium on Computer Modeling and Simulation, p. 1, 2009.

[4] Keirstead, J., Jennings, M. \& Sivakumar, A. A review of urban energy system models: Approaches, challenges and opportunities, Elsevier: London, pp. 3851-3852, 2012.

[5] Perez, D., Kämpf, J.H., Wilke, U. \& Robinson, D. CitySim simulation: the case study of Alt-Wiedikon, a neighborhood of Zürich city, CISBAT: Lausanne, p. 3, 2011. 
[6] Perez, D., Kämpf, J.H. \& Scartezzini, J. Urban Area Energy Flow Microsimulation for Planning Support: a Calibration and Verification Study, International Journal on Advances in Systems and Measurements: Lausanne, p. 264, 2013.

[7] SITG, http://ge.ch/sitg/

[8] Federal Register of Buildings and Dwellings, http://www.bfs.admin.ch/bfs/ portal/en/index/themen/00/05/blank/01.html

[9] Perez, D. A framework to model and simulate the disaggregated energy flows supplying buildings in urban areas, École Polytechnique Fédérale de Lausanne, 2014.

[10] Robinson, D., Computer modelling for sustainable urban design, Earthscan: London, p. 121, 2011. 